\title{
Direct Connection of Supercapacitor-Battery Hybrid Storage System to the Grid-Tied Photovoltaic System
}

\author{
Yoga Sandi Perdana, Student Member, IEEE, S. M. Muyeen ${ }^{\circledR}$, Senior Member, IEEE, \\ Ahmed Al-Durra ${ }^{\circledR}$, Senior Member, IEEE, Helmo Kelis Morales-Paredes ${ }^{\circledR}$, Senior Member, IEEE, \\ and Marcelo Godoy Simões ${ }^{(}$, Fellow, IEEE
}

\begin{abstract}
Penetration rate of grid-connected photovoltaic (PV) generation to the existing utility grid is rapidly increasing over the years. Since the power generated from PV systems fluctuates according to the weather condition, e.g., cloud passing, this can significantly disturb the stability of a weak utility grid. The integration of energy storage devices and its ramp-rate control technique are required to reduce the impact of PV systems output fluctuations and augment the stability of the utility grid. In this paper, ramp-rate control is applied to the direct connection of energy storage devices in PV generation system configuration. The direct connection of supercapacitors string and battery combination scheme is proposed to reduce the number of power converters so that the efficiency of the system is increased. In this work, the PV system output is controlled by directly controlling the energy storage system (ESS) to limit the changing rate of the PV output to a desired ramp-rate value, hence reducing the battery charge/discharge cycles and extending the expected lifetime of the ESS. The performance of the proposed direct connection scheme of the ESS and its ramp-rate control strategy is verified using a 1-kW PV system prototype.
\end{abstract}

Index Terms-Photovoltaic, hybrid energy storage, MPPT, ramp-rate control.

\section{NOMENCLATURE}

$\begin{array}{ll}\text { ESS } & \text { Energy storage system. } \\ \text { PV } & \text { Photovoltaic. } \\ \text { EMS } & \text { Energy management system. } \\ \text { BESS } & \text { Battery energy storage system. } \\ \text { HESS } & \text { Hybrid energy storage system. } \\ \text { SC } & \text { Supercapacitor. } \\ \text { FESS } & \text { Flywheel energy storage system. }\end{array}$

Manuscript received February 19, 2018; revised June 6, 2018 and July 31, 2018; accepted August 10, 2018. Date of publication August 31, 2018; date of current version June 20,2019. This work was supported in part by the São Paulo Research Foundation under Grants 2016/08645-9 and 2017/22629-9. Paper no. TSTE-00144-2018. (Corresponding author: S. M. Muyeen.)

Y. S. Perdana and A. Al-Durra are with the Electrical Engineering Department, Khalifa University of Science and Technology, Abu Dhabi, UAE (e-mail: yosperdana@pi.ac.ae; aaldurra@pi.ac.ae).

S. M. Muyeen is with the Electrical and Computer Engineering Department, Curtin University, Perth, W.A. 6845, Australia (e-mail: Sm.Muyeen@ curtin. edu.au).

H. K. Morales-Paredes is with the Institute of Science and Technology, São Paulo State University, Sorocaba, SP 18087-180, Brazil (e-mail: helmo.paredes @unesp.br).

M. G. Simões is with the Electrical Engineering Department, Colorado School of Mines, Golden, CO 80401 USA (e-mail: msimoes@mines.edu).

Color versions of one or more of the figures in this paper are available online at http://ieeexplore.ieee.org.

Digital Object Identifier 10.1109/TSTE.2018.2868073
UPS Uninterruptable power supply.
MA Moving average.
SoC State of charge.
MPPT Maximum power point tracking.
PQ Power quality.
EDLC Electric double-layer capacitor.
CAES Compressed air energy storage.
LVRT Low voltage ride through.
SC-Battery Combination of supercapacitor and battery.
DRR Desired ramp-rate.
THD Total harmonic distortion.
P\&O Perturb and observe.
IC Incremental impedance.
FOCV Fractional open-circuit voltage.
FSCC Fractional short-circuit current.
EL Electronic load.
PLL Phase-locked loop.
VRLA Valve regulated lead acid.

\section{INTRODUCTION}

D UE to policies from governments around the world to reduce greenhouse effect caused by the burning of fossil fuels, the penetration of the power generated by renewable energy sources has been increasing rapidly. In 2014, it was reported that the total installed capacity of solar power generation was increased more than 8 times within the period 2009-2014 (from $20.4 \mathrm{GW}$ to $177 \mathrm{GW}$ ) [1]. This represents about $1 \%$ of the world's generated electricity. One example of those governmental policies is the feed-in tariff incentives for photovoltaic (PV) power that is supplied to the utility grid. The feed-in tariff incentives state that for generated PV power, the electric utility company has to buy it with a price higher than the economic price of power generated from conventional sources. For example, in France, the electric utility company has to buy the electricity generated from PV systems for $€ 0.60 / \mathrm{kWh}$, but on the other hand, the price is $€ 0.10 / \mathrm{kWh}$ when it is bought from the utility company [2]. Furthermore, the production cost of the PV module is reduced, making the return on investment of grid-connected PV systems more cost-effective. Therefore, it encourages people to install grid-connected PV systems.

Another advantage of grid-connected PV systems is that storage devices and charge regulator are not required as the excess, or lack of power will be absorbed or supplied by the utility grid. This can reduce the cost of a grid-connected PV system to $40 \%$ 
less than the cost of a stand-alone PV system [3]. Today, the number of grid-connected PV systems installations dominates the off-grid (stand-alone) PV systems. Typically, a PV string is interconnected to the grid through a grid-tied solar inverter. What commercially named "grid-tied solar inverter" is actually consisted of a DC-DC converter (Buck/Boost) for maximum power point tracking (MPPT) and a DC-AC inverter to maintain constant DC voltage and control real/reactive power flow to the grid and power quality (PQ) improvement [4], [5]. As there is two stages of conversion, DC-DC, and DC-AC, the structure is named dual-stage inverter.

However, since the output of the PV system is highly influenced by the weather conditions, grid characteristic, and geographical distribution of PV arrays within the grid, the integration of PV systems to the utility grid becomes a major challenge [6]. The high penetration rate of grid-connected PV systems can affect the operation of the existing utility grid, especially during fast fluctuations of PV power output due to intermittency and unpredictability nature of the large scale PV plant [7], [8]. Solution to the fluctuating output is by integrating a storage system into the grid-connected PV system to utilize the energy management system (EMS). Therefore, the combination of a PV system and an energy storage system (ESS) is necessary in some cases, to meet the standards set by the transmission system operator [8]-[11]. The ESS can offer many possibilities to improve the grid performance. However, there is no energy storage technology and effective energy management to guarantee all features needed for proper integration with the grid [8], [12]-[15].

In [16], ramp-rate control of a PV system with a battery energy storage system (BESS) and conventional source in stand-alone DC microgrid is presented. The ramp-rate control aims to limit the rate of change of PV output according to the grid capability to compensate PV power changes. The hierarchical control strategy is used to maintain the bus voltage, achieve voltage regulation capability, and handles extreme operating conditions of the DC microgrid. A ramp-rate control of a grid-connected PV system using electric double layer capacitor (EDLC) is demonstrated in [17]. Both of the ESSs require a high installation cost to achieve the ramp-rate control capability, power, and energy capacity.

Hybrid energy storage system (HESS) which takes the advantages of each ESS while having lower installation cost is shown to be an effective and economical solution [18]. A hybrid of a supercapacitor (SC) and battery storage system is used to compensate the fluctuation of the power generation of PV-base DC grid in [19]. SCs which have high power capacity is used to balance the fast changes of PV output, whereas battery is used to balance slow changes of PV output. Hence, the lifespan of the battery is extended due to less current stresses. Another type of ESS, which has high power capacity characteristic is the flywheel energy storage system (FESS). Despite its benefits, the installation cost of FESS is relatively expensive. Therefore, a hybrid of FESS and conventional diesel generator is used to replace uninterruptable power supply (UPS) unit in [20]. The FESS is shown to be able to reduce the cost and extend the lifetime compared to the UPS unit.
One important factor, which determines the size of the storage system, is the calculation of the power command for the power converter [21]. The simple method to generate power command for the inverter is by using moving average (MA) method. The disadvantage of the ramp-rate control based on MA method is the introduction of delays caused by memory effect [22]. In [23], the ramp-rate control is carried out by varying the state of charge $(\mathrm{SoC})$ of the ESS as a function of actual PV power and the possible production limit. However, in this method, the frequency of using the ESS is also relatively high. Both of the methods can cause a reduction in the lifetime of the ESS. Therefore, in this work, the reference for the power converter is generated directly by limiting the ramp-rate of PV output to omit the memory effect. This could reduce the storage charging/discharging operation and extend the lifetime of the ESS.

A power converter is necessary for the integration of energy storage into the grid-tied PV system. However, it increases the cost and power losses. Hence, several direct integration schemes of ESS into renewable energy sources have been studied. A dual inverter topology which is used for interfacing SC bank and grid connection is deployed to reduce additional cost and power losses from DC-DC converter [24]. A combination of compressed air energy storage (CAES) and SC which is directly connected to the DC-link of the PV system is presented in [25]. However, both in [17] and [25], the MPPT algorithm is not taken into account when SC bank is directly connected to the system. A multi-mode operation of PV system with low voltage ride through (LVRT) capability to extract maximum power from the PV using an interleaved boost converter during LVRT is studied in [26].

For grid-tied PV systems with two-stage (DC-DC converter and DC-AC inverter) power conversion, an ESS is connected at the DC-link in some cases, to add smoothing feature or when the contribution is required in load management. However, there are some system-level compatibility issues between these power converters (DC-DC unidirectional, DC-DC bidirectional, DC$\mathrm{AC}$ inverter) which require careful design or selection of inverters. The issue becomes more prominent when the converters are purchased from different vendors, i.e., compatibility issue. Developing a system combining all features may resolve the issue and objective of this work. Therefore, in this study, a new HESS based on a direct connection to a series combination of supercapacitor and battery (SC-battery), as shown in Fig. 1, is proposed. The salient feature of the proposed scheme and control is that it performs the ramp-rate control of the output power of the PV even without the addition of the power converter; meanwhile, it applies MPPT algorithm to extract the maximum power from the PV array. The control strategy can be divided into two working modes, the first mode is the MPPT mode which is applied when the PV output rate of change is below the desired ramp-rate (DRR). The other mode is the Power Smoothing mode which is applied during the fluctuating PV output or when the ramprate of the PV output exceeds the DRR. Moreover, a novel switching and control scheme is developed for the proposed HESS. The effectiveness of the proposed configuration control is 


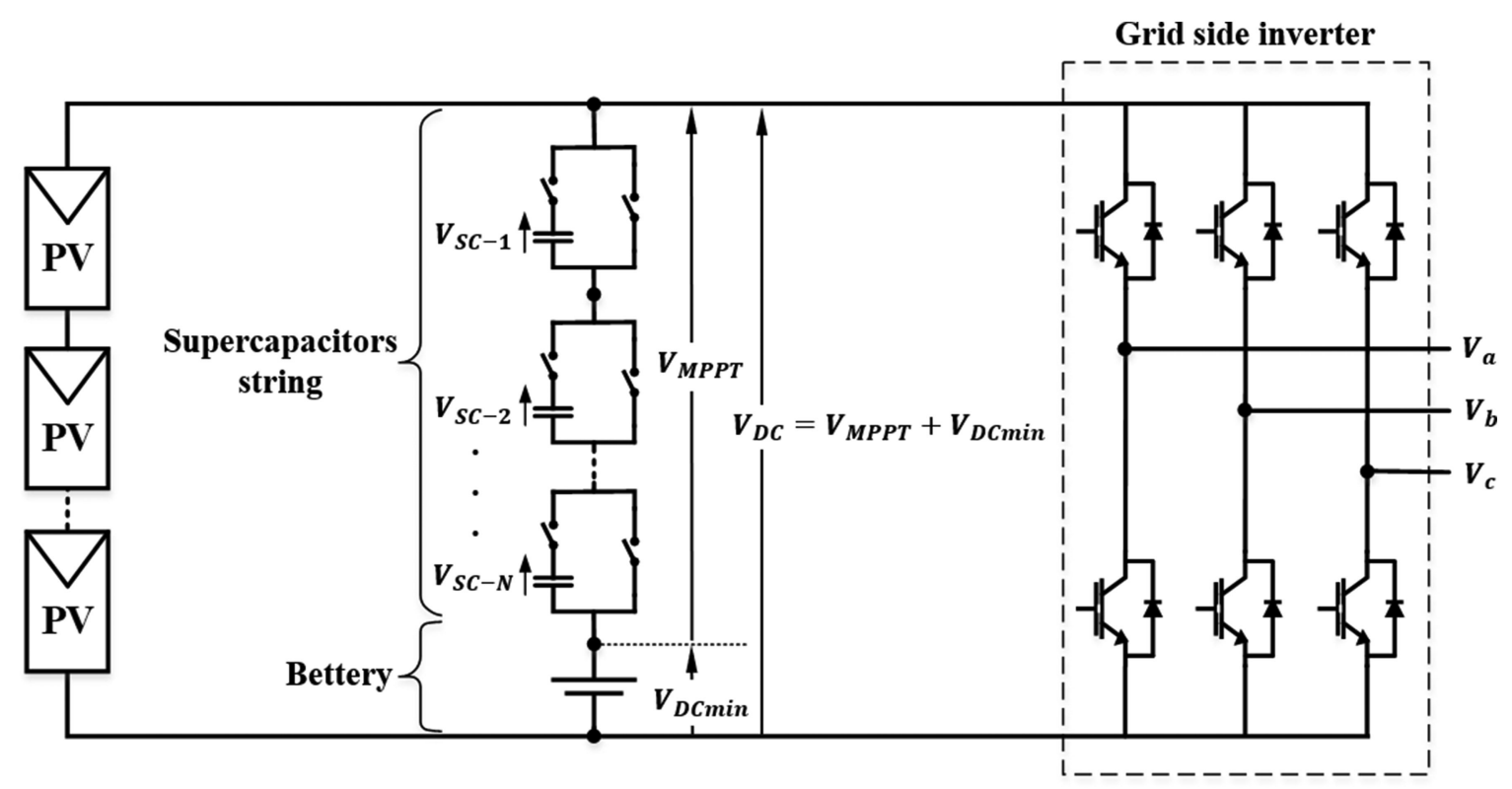

Fig. 1. Direct connection scheme of supercapacitor-battery hybrid storage system.

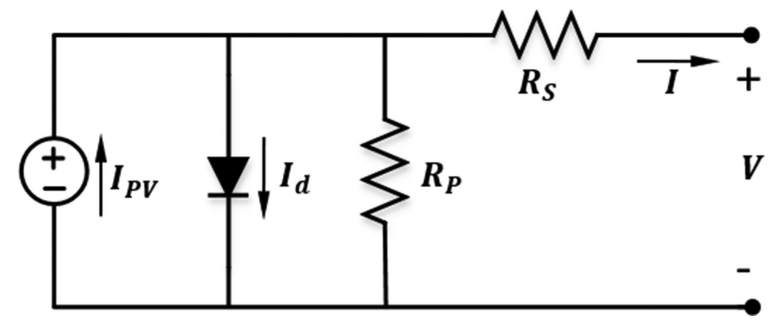

Fig. 2. Practical model of a PV module.

validated using simulation in MATLAB/Simulink environment and laboratory-scale experimental setup.

\section{GRID TIED PV SySTEM}

The typical topology of the grid-tied PV system consists of PV array, DC-DC converter, DC-link capacitors, and grid-tied inverter. The function of the DC-DC converter is to carry out the MPPT algorithm to extract maximum power from the PV. However, unlike the typical DC-DC topology, the PV array is directly connected to an SC-battery as it is also able to perform the MPPT algorithm.

\section{A. PV Array Model}

A PV module consists of some PV cells which are semiconductor materials similar to PN junction diode to directly convert sunlight (photons) into electricity (electron charges) or electric current. Several PV modules can be connected in series to make PV string. Several PV strings can be combined in parallel to create PV array. A practical model of a single PV module is shown in Fig. 2 [27]. The PV system parameters used in the simulation is also taken from the same source. PV modules are combined in series or parallel to obtain a certain voltage and power. Therefore, an aggregated model is used in the simulation study, as explained in [28]. The output current and voltage of the aggregated model is expressed by:

$$
\begin{aligned}
I= & N_{P} I_{P V}-N_{P} I_{0}\left[\exp \left(\frac{q\left(V+\frac{N_{S} R_{S}}{N_{P}} I\right)}{N_{C} N_{S} a k T}-1\right)\right] \\
& -\frac{V+\frac{N_{S} R_{S}}{N_{P}} I}{\frac{N_{S} R_{P}}{N_{P}}}
\end{aligned}
$$

where $I_{P V}$ and $I_{0}$ are the photo-current and reverse saturation current of the PV module respectively. $N_{S}$ is the number of series consented modules in a string, $N_{P}$ is the number of strings connected in parallel, $N_{C}$ is the number of series connected cells, $R_{S}$ is the equivalent series resistance of the array and $R_{P}$ is the equivalent parallel resistance.

\section{B. Modeling and Control of the Grid-Tied Inverter}

Three-phase inverter with L-filter model is chosen as the model of the grid-side inverter of the proposed topology of PV system under study. The grid-side of the three-phase inverter is regulated by the following equations [29]:

$$
\begin{aligned}
\frac{d i_{a}}{d t} & =-\frac{R}{L} i_{a}-\frac{1}{L} e_{a}+\frac{v_{d c}}{L} S_{a} \\
\frac{d i_{b}}{d t} & =-\frac{R}{L} i_{b}-\frac{1}{L} e_{b}+\frac{v_{d c}}{L} S_{b} \\
\frac{d i_{c}}{d t} & =-\frac{R}{L} i_{c}-\frac{1}{L} e_{c}+\frac{v_{d c}}{L} S_{c}
\end{aligned}
$$

where $S_{a}, S_{b}$, and $S_{c}$ are the inverter switching signal input. By applying Park's transformation, time invariant model in the $\mathrm{dq}$ frame rotating, at grid angular frequency $\omega$, the differential 


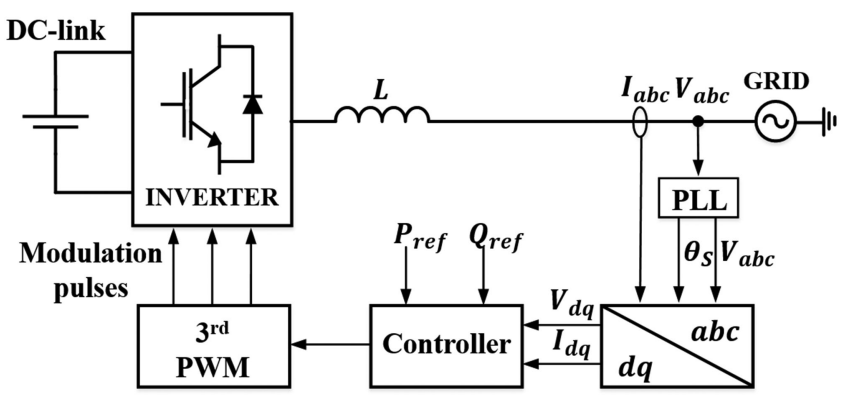

Fig. 3. Grid-tied inverter and its control diagram.

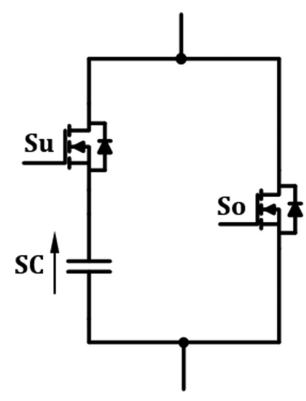

Fig. 4. One single SC unit.

equations can be obtained as:

$$
\begin{aligned}
\frac{d i_{d}}{d t}-\omega i_{q} & =\frac{1}{L}\left[-R i_{d}-e_{d}+S_{d} v_{d c}\right] \\
\frac{d i_{q}}{d t}+\omega i_{d} & =\frac{1}{L}\left[-R i_{q}-e_{q}+S_{q} v_{d c}\right]
\end{aligned}
$$

where $S_{d}$ and $S_{q}$ are the switching signal input and $i_{d}$ and $i_{q}$ are the output. By using a phase-locked loop (PLL) [30] to estimate angular position $\theta$ such that $e_{q}$ is equal to zero and assuming the system is working in unity power factor, from the instantaneous power theory, the reference for the controller of the three-phase inverter can be computed as:

$$
\begin{aligned}
I_{\text {dref }} & =\frac{2}{3} \frac{P_{r e f}}{E_{d}} \\
I_{\text {qref }} & =0
\end{aligned}
$$

where $E_{d}$ is equal to the amplitude of the grid voltage. Therefore, the active power transmitted to the grid can be controlled by giving the reference $P_{r e f}$ to the inverter. The model of the gridtied inverter and its control diagram are shown in Fig. 3.

\section{Proposed Direct ConNection Scheme OF SUPERCAPACITOR-BATTERY}

Instead of using conventional electrolytic capacitors, a string of supercapacitors is used as the DC-link capacitor for the proposed direct connection scheme shown in Fig. 1. The string is arranged from several SC units connected in series. This SC unit is illustrated in Fig. 4. A single SC unit consists of one $\mathrm{SC}$ with maximum voltage $2.7 \mathrm{~V}$ and two switches, Su and So. These switches work in opposite way which means that when one switch is closed, the other is opened, and vice versa.

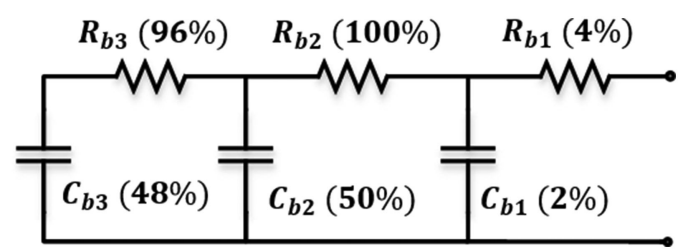

Fig. 5. Distributed model of the supercapacitor.

TABLE I

DISTRIBUTED PARAMETERS OF THE SUPERCAPACITOR

\begin{tabular}{cc}
\hline \hline Capacitance & Resistance \\
\hline$C_{b 1}=13 \mathrm{~F}$ & $R_{b 1}=0.032 \mathrm{~m} \Omega$ \\
$C_{b 2}=325 \mathrm{~F}$ & $R_{b 2}=0.8 \mathrm{~m} \Omega$ \\
$C_{b 3}=312 \mathrm{~F}$ & $R_{b 3}=0.768 \mathrm{~m} \Omega$ \\
\hline \hline
\end{tabular}

Therefore, the voltage of one SC unit is a function of the switch state where the value is equal to either the SC voltage or zero.

$$
V_{u n i t}\left(S_{u}\right)= \begin{cases}V_{S C}, & \text { for } S_{u}=1 \\ 0, & \text { otherwise. }\end{cases}
$$

The voltage of the SC unit has to be chosen such that it still can absorb or supply power without overcharging or undercharging the supercapacitor since these could shorten the cycle of life of the supercapacitor. The optimal voltage of the SC unit is computed so that it corresponds to the $50 \%$ of the $\mathrm{SoC}$ as in [31]. By choosing the limit of the minimum voltage of the SC unit equal to the half of its rated voltage, the optimum voltage of the SC unit can be determined using:

$$
V_{S C}=\sqrt{k_{o p} V_{S C-\text { rated }}^{2}}
$$

where $k_{o p}$ is a constant which value is equal to 0.625 to obtain optimum charge of the supercapacitor and $V_{S C-\text { rated }}$ is the rated voltage of the supercapacitor.

The required number of $\mathrm{SC}$ units then can be determined from the required variations of the DC-link voltage and the optimum voltage of the $\mathrm{SC}$ unit as:

$$
N_{S C}=\operatorname{round}\left(\frac{\Delta V_{M P P}}{V_{S C}}\right)
$$

where is $N_{S C}$ the minimum required numa ber of the SC units and $\Delta V_{M P P}$ is the voltage variations of the DC-link required to apply the MPPT technique. A distributed model is used in the simulation study where three $\mathrm{RC}$ branches is used to characterize the terminal behaviour of SC [32]. The distributed model is shown in Fig. 5. The parameters are based on the datasheet of BCAP0650 from Maxwell Technologies. The parameters of the supercapacitor used in the simulation are listed in Table I.

From the relation of the MPP voltage, $V_{M P P}$, and the solar irradiance of the PV array is shown in Fig. 6, the variation of the DC-link voltage is chosen so that the PV operates in the closely linear region for the easiness in the control and operation. The voltage of the battery is then determined accordingly as the 


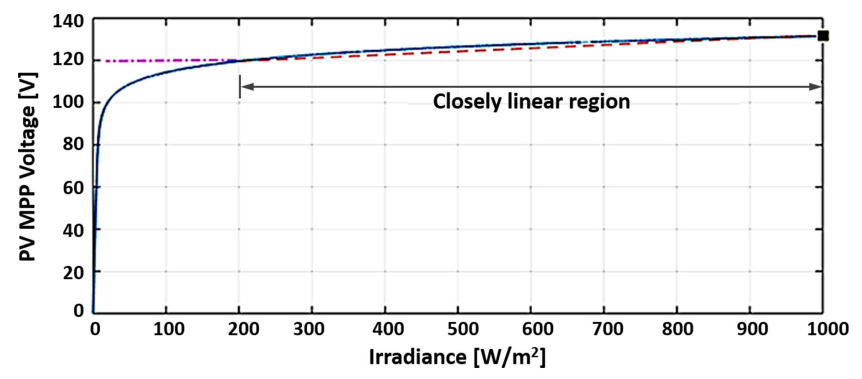

Fig. 6. Distributed model of the supercapacitor.

minimum operating voltage of the PV array to operate in the closely linear region in order for the inverter to transmit current within allowable total harmonic distortion (THD) limit to the grid [33].

A simple electrical model of a battery which is represented by a single voltage source, $E_{b}$, and a resistor, $R_{b}$, is used for the simulation study [34]. $E_{b}$ is the open-circuit voltage of the battery and $R_{b}$ is the internal series resistance of the battery to represent the battery internal voltage drop. Thus, the terminal voltage of the battery, $V_{b a t t}$, is then equal to the $E_{b}$ plus/minus the voltage drop in the internal resistor $\left(V_{b a t t}=E_{b} \pm I R_{b}\right)$. The current $I$ is positive during charge and negative during the discharge. The battery model used in this work is based on the 12 V Deep Cycle AGM (U1-AGM) - VRLA battery from Trojan Battery Company. The capacity of the battery are $33 \mathrm{Ah}$ and $29 \mathrm{Ah}$ at 20 hour and 5 hour of usage respectively.

\section{Control Strategy FOR the Proposed Direct CONNECTION SCHEME}

The main idea of the control strategy for the proposed direct connection scheme is to split the operations of the proposed direct configuration into two working modes. These modes are MPPT or normal mode which is applied when the rate of change of the PV output is less than the DRR and ramp-rate control mode which is applied when the rate of changes of PV output is exceeding the DRR. In the first mode, the MPPT technique is applied to extract maximum power from the PV array. In latter mode, the MPPT is not applied, and the storage device is used to absorb/supply power to directly limit the ramp-rate of the power output of the PV system. By directly controlling the ramp-rate, it is expected that the storage device is used less frequent since there is no memory effect coming from the conventional MA method.

\section{A. MPPT Mode}

The current generated by the PV array, $I_{P V}$, is influenced by solar irradiance and temperature. A MPPT technique is applied to match the operating voltage or current such that maximum power output for a certain irradiance and temperature can be extracted from a PV array [35]. There are many types of MPPT techniques, some of the most widely used are Perturb and Observe (P\&O), Incremental Conductance (IC), Fractional OpenCircuit Voltage (FOCV), and Fractional Short-Circuit Current (FSCC). Fractional Open-Circuit Voltage (FOCV) is used in this study due to its simplicity though other MPPT techniques can also be applied to give more accurate maximum power point.

The FOCV technique derived from the closely linear relation characteristic of PV maximum power point, $V_{M P P}$, and open circuit voltage, $V_{O C}$, for various irradiances. Hence $V_{M P P}$ can be approximated as a fraction of $V_{O C}$ as:

$$
V_{M P P} \approx k_{M P P} x V_{O C}
$$

where $k_{M P P}$ is a constant which is approximated as 0.8 of the $V_{O C}$ for the PV module used in this study. In order to avoid temporary loss of power when PV is disconnected to measure the $V_{O C}$, a pilot cell is optimally chosen from a PV module to represent the $V_{O C}$ of the entire PV module without disconnecting the PV module.

The MPPT voltage variation is carried out by the SC string. The number of the connected/disconnected SC is then determined according to the $V_{M P P}$ reference obtained from FOCV method and the actual DC-link voltage, $V_{D C}$. The number of the connected SC unit as a function of $\Delta V_{d i f f}=V_{M P P}-V_{D C}$ is:

$$
N\left(\Delta V_{\text {diff }}\right)= \begin{cases}N^{\prime}-1, & \text { for }\left(\Delta V_{\text {diff }}\right) \leq-\frac{V_{S C}}{2} \\ N^{\prime}+1, & \text { for }\left(\Delta V_{\text {diff }}\right) \geq \frac{V_{S C}}{2}\end{cases}
$$

where $N$ is the number of the connected SC units and $N^{\prime}$ is the previous number of connected SC units.

The super-capacitor units are connected/disconnected in First-In-First-Out (FIFO), as discussed in [36], maintaining the voltage balance for each unit. In this algorithm, the shifting orders of the SC units are organized such that the first unit to be active is also the first to deactivate and vice versa. This method is implemented by counting the loading of each SC units. The longest active unit has the highest loading. When the unit is deactivated, the loading is reset to zero. Therefore, the FIFO is applied by turning off the unit with the highest loading first and turning on the unit next to the last active unit.

\section{B. Ramp-Rate Control Mode}

As irradiance and temperature are varied depend on the weather condition, such as moving cloud, PV output is also varying. Ramp-rate control aims to limit PV output rate of changes according to the desired ramp-rate and minimize its disturbances on the grid stability. The power supplied to the grid is not only from the PV but also from the battery. The battery absorbs/supplies power to perform the ramp-rate control. In this mode, the only battery is connected to the DC-link. The MPPT is not applied, and the number of the connected SC units, $N$, from (7) is set to zero.

In the proposed system, the power transmitted to the grid is governed by the grid-side inverter such that its rate of change is limited directly according to the DRR. When $\frac{d P_{p v}}{d t}$ is greater than the DRR, the reference given to the inverter is computed so that its rate of change is equal to the DRR, in the discrete form, as:

$$
\frac{\Delta P_{p v}}{\Delta t}=D R R
$$




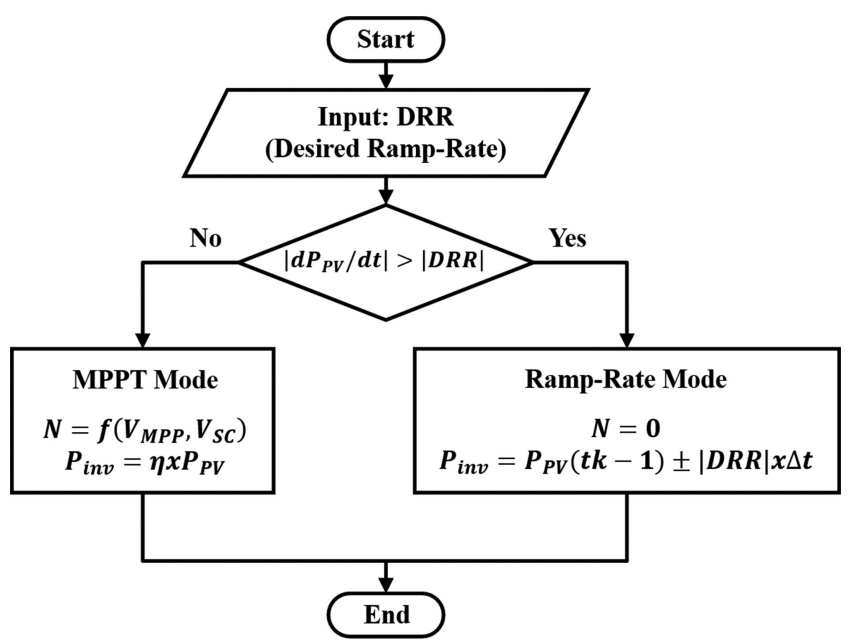

Fig. 7. Flowchart of the mode switching function.

From equation (10), reference for the inverter is then can be determined using:

$$
P_{i n v}=P_{p v}^{\prime} \pm|D R R| x \Delta t
$$

where $P_{p v}^{\prime}$ is the previous value of $\mathrm{PV}$ output and $\Delta \mathrm{t}$ is sampling time.

In another case, when $\frac{d P_{p v}}{d t}$ is less than the DRR, the reference of the inverter is determined so that all the power generated by the PV array is transmitted to grid as:

$$
P_{i n v}=\eta_{i n v} x P_{p v}
$$

where $\eta_{i n v}$ is the efficiency of the inverter.

Thus, the reference for the grid-side inverter as a function of the PV output rate of change, $\frac{d P_{p v}}{d t}$, is:

$$
\begin{aligned}
& P_{i n v}\left(\frac{d P_{p v}}{d t}\right) \\
& =\left\{\begin{array}{c}
\eta_{i n v} x P_{p v}, \text { for } \frac{d P_{p v}}{d t} \leq D R R \\
P_{p v}^{\prime} \pm|D R R| x \Delta t, \text { for } \frac{d P_{p v}}{d t}>D R R
\end{array}\right.
\end{aligned}
$$

\section{Switching Mode}

The switching between MPPT and Ramp-rate Control mode is determined by the rate of change of the $\mathrm{PV}$ power output, $\frac{d P_{p v}}{d t}$. When $\frac{d P_{p v}}{d t}$ is less than or equal DRR, the sy to tostem works in the MPPT mode; otherwise, it goes to the Ramp-rate control mode. The flowchart of this switching function is illustrated in Fig. 7.

\section{Simulation Results}

The validity of the proposed configuration and its control strategy is verified using MATLAB/Simulink. Solar irradiance data were taken in The Petroleum Institute, Abu Dhabi, UAE, on November 7, 2008, shown in Fig. 8 is used to verify the effectiveness of the system. The power changes rapidly when the moving clouds cover the PV panels. The DRR is $5 \% / \mathrm{min}$.

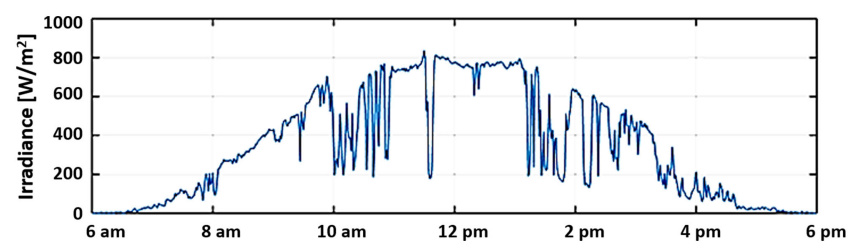

Fig. 8. Solar irradiance data.

TABLE II

SYSTEM PARAMETERS FOR SimULATION

\begin{tabular}{cc}
\hline \hline Parameter & Value \\
\hline PV array rating & $1000 \mathrm{~W}$ \\
Battery voltage & $120 \mathrm{~V}$ \\
Battery capacity & $33 \mathrm{Ah}$ \\
Grid voltage & $66 \mathrm{~V}$ \\
Filter inductance & $12 \mathrm{mH}$ \\
Frequency & $50 \mathrm{~Hz}$ \\
\hline \hline
\end{tabular}

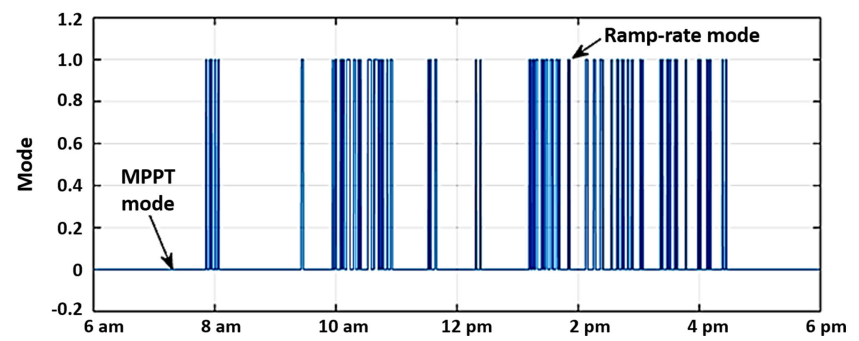

Fig. 9. Operating modes.

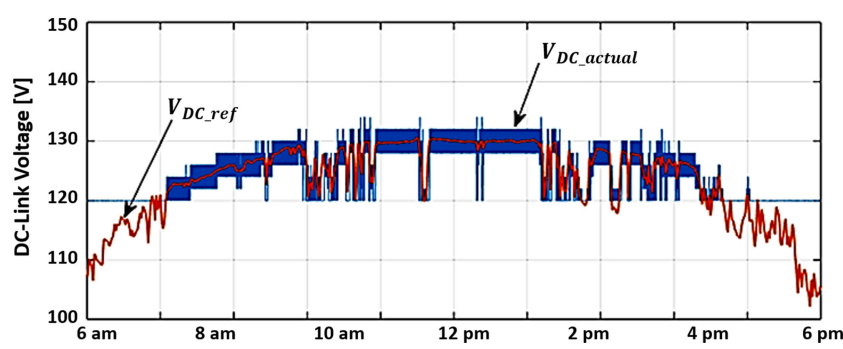

Fig. 10. DC-link voltage.

The DC voltage varies from 120 to $132 \mathrm{~V}$. The parameters of the simulations are presented in Table II.

The operating mode during the 12-hour interval is shown in Fig. 9. It can be seen that when the PV output changes very fast, the system works in ramp-rate mode, otherwise in MPPT mode. Also, during a rapid fluctuation of the solar irradiation, the working mode is switched merely several times from 1 PM to 2 PM span. Hence, it can be observed that the smallest switching frequency is in order of a minute. The simulation result related to the MPPT mode is shown in Fig. 10. As can be seen, the DC-link voltage follows the reference MPPT voltage. 


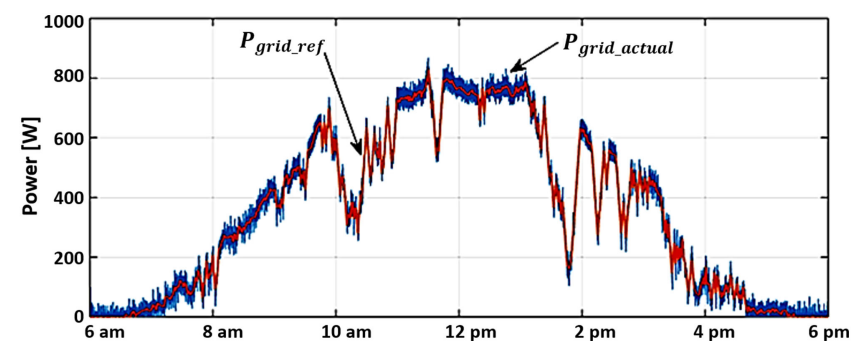

(a)

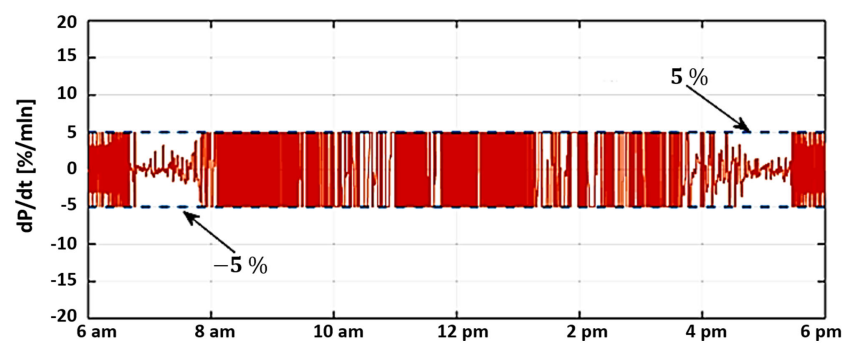

(b)

Fig. 11. Power transmitted to the grid. (a) P. (b) $d P / d t$.

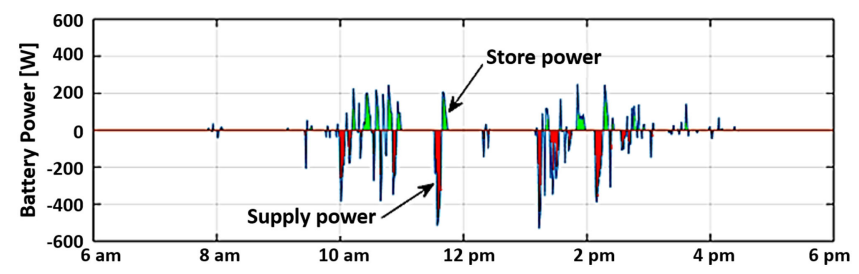

Fig. 12. Battery charge/discharge operation using the proposed method.

The voltage varies in a step fashion since it is performed by connecting/disconnecting the SC units. However, the MPPT is not applied when the reference is below the battery voltage due to a limitation in the DC-link voltage variations. The MPPT effectiveness can be improved by using smaller voltage step change. Fig. 11(a) shows the power transmitted by the inverter using the ramp-rate control strategy. Its rate of change is shown in Fig. 11(b). It can be seen that the rate of change is limited within $5 \% / \mathrm{min}$ or $50 \mathrm{~W} / \mathrm{min}$ for $1 \mathrm{~kW}$ PV system. Hence, the MPPT and ramp-rate control strategies of the proposed directconnection scheme are valid.

The charging/discharging cycles of the battery operations to absorb/supply the differences between the PV power output and the power transmitted to the grid of the ramp-rate control strategy for the direct connection scheme is shown in Fig. 12. It can be seen that the area under the graph for the direct ramprate control applied to the direct connection scheme is relatively small. It means that the operations of the battery are less frequent which resulted in the lifetime extension of the batteries.

\section{EXPERIMENTAL RESULTS}

The experimental setup for the validation of the direct connection of supercapacitor-battery HESS scheme is shown in

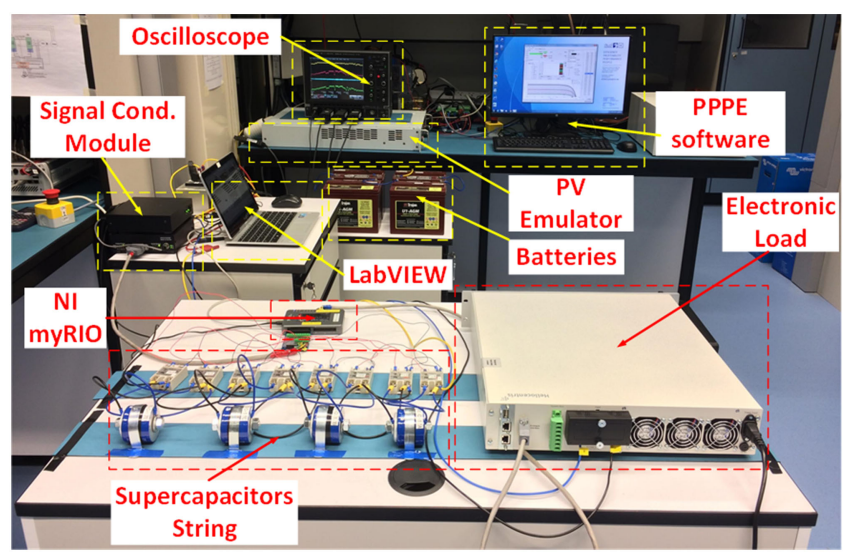

Fig. 13. Experimental setup.

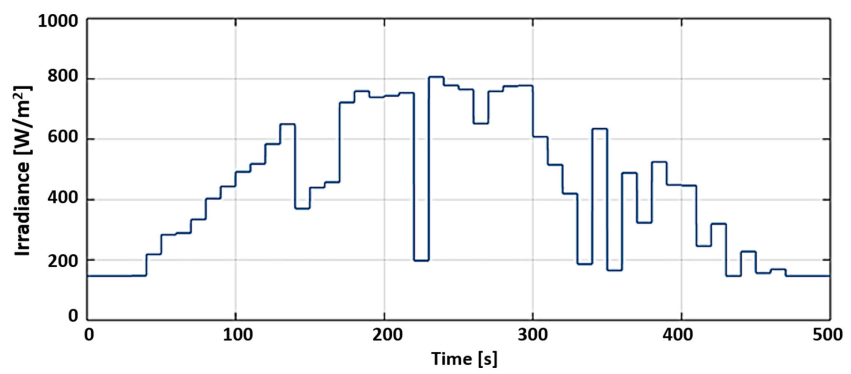

Fig. 14. Sampled irradiance data.

Fig. 13. The setup consists of a Magna-Power $160 \mathrm{~V} 12 \mathrm{~A}$ programmable DC power supply (XR series) with Photovoltaic Power Profile Emulation software to emulate PV array, 4 units of $2.7 \mathrm{~V} 650 \mathrm{~F}$ BCAP0650 supercapacitors and switches for the SC string, 4 units U1-AGM 12 V 33 Ah VRLA batteries, a Heliocentric $2.4 \mathrm{~kW}$ electronic load (EL2400). Furthermore, a NI myRIO real-time embedded platform is utilized to implement the controller in order to verify the proposed scheme and control. The currents and DC-link voltage waveform are captured using Teledyne LeCroy WaveSurfer MXs-B Oscilloscopes.

The parameters used in the simulation are scaled down to $400 \mathrm{~W}$ to suit the rating of the hardware equipment. A sampling of representative solar irradiance data shown in Fig. 14 is used for the input for the PV emulator in this experimental validation. These sampled irradiance data points which consist of 50 points are equivalent to shown in Fig. 8 in where each point are emulated for $10 \mathrm{~s}$. The sampled points include the worst case scenario where the solar irradiance changes drastically around the noon to test the ramp-rate control strategy. From the DClink voltage shown in Fig. 15, the DC-link voltage changes in a step fashion according to the irradiance data so that the PV operates at its MPPT. The PV current, dc-link current, and grid current are shown in Fig. 16(a), Fig. 16(b), and Fig. 16(c) respectively. The reference is given to the electronic load (EL) which act as if it is the inverter and the grid is computed using the control strategy illustrated in Fig. 7. Therefore, the EL controls the power that is going/coming from the batteries to 


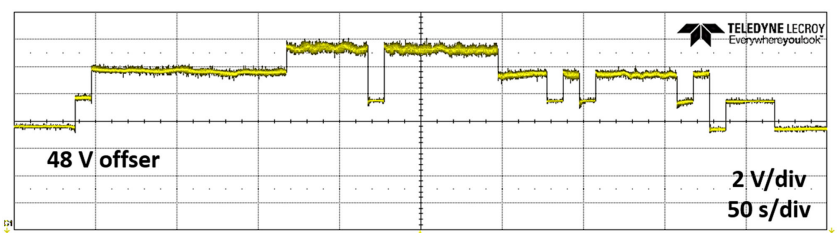

Fig. 15. DC-link voltage.

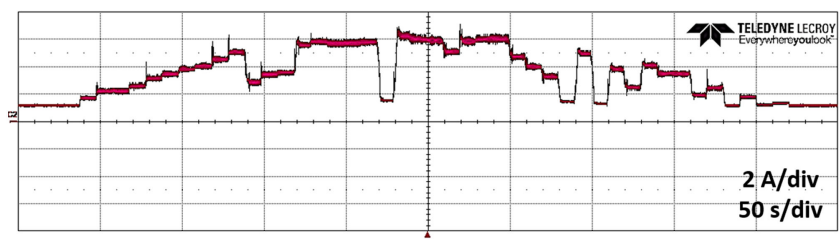

(a)

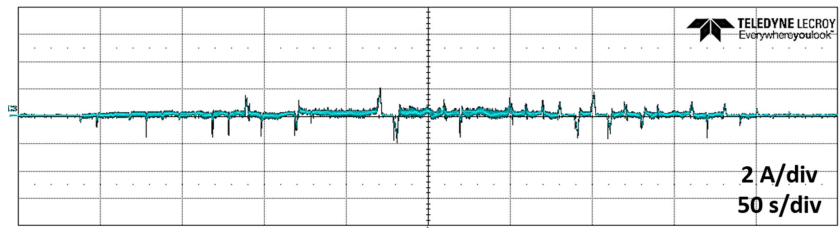

(b)

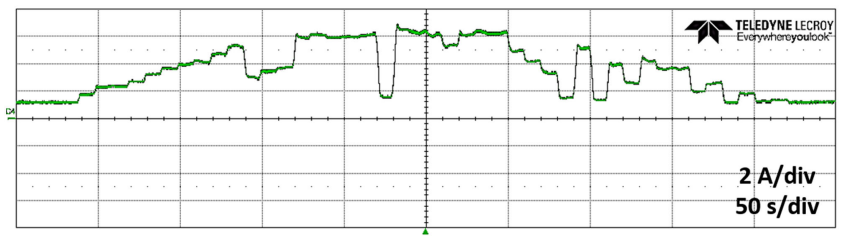

(c)

Fig. 16. Balance of currents at DC-link. (a) PV current $\left(I_{p v}\right)$. (b) battery current $\left(I_{d c}\right)$. (c) Grid current $\left(I_{g}\right)$.

limit the power which is sent to the grid. As it can be seen from the DC-link current in Fig. 16(b), the batteries absorb/supply power when there are changes in the PV power which is greater than the DRR. From the result, it can be confirmed that the proposed direct connection scheme of the SC-battery HESS and its control strategy can limit the ramp-rate of the power output according to the desired value while also maintaining the MPPT operations.

This paper studied how ramp control would work with variable irradiance to control the SC bank in the DC link. A realistic irradiance profile takes a time window of hours, from sunrise to sunset. To mimic this characteristics, in our laboratory, we programmed a power supply to behave as the solar irradiation with a profile that takes 500 seconds in order to represent a time window of 12 hours. In other words, a long time-frame is realized in a small time-frame, for the sake of quick experimental validation, in lab scale. Since this system is capable of responding to such a quicker emulated irradiance data, it is expected that the control is valid for realistic solar irradiance pattern.

\section{CONCLUSION}

A direct connection configuration of a combination of supercapacitors and battery was proposed. The proposed system reduces compatibility issues of the unidirectional DC-DC converter used for PV MPPT and bi-directional DC-DC converter for ESS charging/discharging, especially when they are from the different manufacturer. The control strategy divides the working mode into MPPT mode and ramp-rate control mode. The MPPT mode is carried out by an SC string whose voltage varies by connecting/disconnecting the $\mathrm{SC}$ unit. For the ramp-rate control mode, the SC string is bypassed, and only battery is connected to perform the ramp-rate control. The proposed configuration and its control strategy have been verified through simulations in MATLAB/Simulink environment, and it was validated through laboratory scale real-time hardware implementation. It has been found that the proposed control strategy can be implemented in the proposed scheme to limit the ramp-rate of the PV power output. By using the proposed control strategy, the battery is charged/discharged relatively less frequent; hence, the lifetime of the ESS could be extended.

\section{REFERENCES}

[1] IEA and PVPS, "Trends in photovoltaic applications: Survey report of selected IEA countries between 1992 and 2006," Surv. Rep. IEA-PVPS T1-16, 2007. [Online]. Available: http://iea-pvps.org/

[2] D. Rekioua and E. Matagne, Optimization of Photovoltaic Power Systems: Modelization, Simulation and Control. New York, NY, USA: Springer, 2012.

[3] A. Labouret and M. Villoz, Solar Photovoltaic Energy, vol. 9. Stevenage, U.K.: IET, 2010.

[4] F. Spertino and G. Graditi, "Power conditioning units in grid-connected photovoltaic systems: A comparison with different technologies and wide range of power ratings," Sol. Energy, vol. 108, pp. 219-229, 2014.

[5] Y. Yang, F. Blaabjerg, H. Wang, and M. G. Simões, "Power control flexibilities for grid-connected multi-functional photovoltaic inverters," in Proc. Int. Workshop Integr. Sol. Power Power Syst., Nov. 2014, pp. 233-239.

[6] M. S. ElNozahy and M. M. A. Salama, "Technical impacts of gridconnected photovoltaic systems on electrical networks-A review," J. Renew. Sustain. Energy, vol. 5, no. 3, 2013, Art. no. 032702.

[7] R. Van Haaren, M. Morjaria, and V. Fthenakis, "An energy storage algorithm for ramp rate control of utility scale pv (photovoltaics) plants," Energy, vol. 91, pp. 894-902, 2015.

[8] A. Zahedi, "Maximizing solar PV energy penetration using energy storage technology," Renew. Sustain. Energy Rev., vol. 15, pp. 866-870, 2011.

[9] J. Marcos, O. Storke"1, L. Marroyo, M. Garcia, and E. Lorenzo, "Storage requirements for pv power ramp-rate control," Sol. Energy, vol. 99, pp. 28$35,2014$.

[10] M. G. Ippolito, E. Telaretti, G. Zizzo, and G. Graditi, "A new device for the control and the connection to the grid of combined RES-based generators and electric storage systems," in Proc. 4th Int. Conf. Clean Electr. Power Renew. Energy Resour. Impact, 2013, pp. 262-267.

[11] G. Graditi, R. Ciavarella, M. Valenti, G. Ferruzzi, and G. Zizzo, "Frequency stability in microgrid: Control strategies and analysis of BESS aging effects," in Proc. Int. Symp. Power Electron., Electr. Drives, Autom. Motion, 2016, pp. 295-299.

[12] Y. Yang, L. Niu, J. Jiang, Y. Boa, and D. Zhang, "Research on battery storage system configuration in active distribution networks," Int. J. Smart Grid Clean Energy, vol. 4, no 1, pp. 38-44, 2014.

[13] E. Telaretti, G. Graditi, M. G. Ippolito, and G. Zizzo, "Economic feasibility of stationary electrochemical storages for electric bill management applications: The italian scenario," Energy Policy, vol. 94, pp. 126-137, 2016.

[14] T. M. I. Mahliaab, T. J. Saktisahdana, A. Jannifarc, M. H. Hasanc, and H. S. C. Matseelar, "A review of available methods and development on energy storage; technology update," Renew. Sustain. Energy Rev., vol. 33, pp. 532-545, 2014. 
[15] O. M. Toledo, D. O. Filho, and A. S. A. C. Diniz, "Distributed photovoltaic generation and energy storage systems: A review," Renew. Sustain. Energy Rev., vol. 14, no. 1, pp. 506-511, 2010.

[16] C. Jin, P. Wang, J. Xiao, Y. Tang, and F. H. Choo, "Implementation of hierarchical control in dc microgrids," IEEE Trans. Ind. Electron., vol. 61, no. 8, pp. 4032-4042, 2014.

[17] N. Kakimoto, H. Satoh, S. Takayama, and K. Nakamura, "Ramp-rate control of photovoltaic generator with electric double-layer capacitor," IEEE Trans. Energy Convers., vol. 24, no. 2, pp. 465-473, Jun. 2009.

[18] J. Xiao, P. Wang, and L. Setyawan, "Hierarchical control of hybrid energy storage system in dc microgrids," IEEE Trans. Ind. Electron., vol. 62, no. 8, pp. 4915-4924, Aug. 2015.

[19] S. K. Kollimalla, M. K. Mishra, and N. L. Narasamma, "Design and analysis of novel control strategy for battery and supercapacitor storage system," IEEE Trans. Sustain. Energy, vol. 5, no. 4, pp. 1137-1144, Oct. 2014.

[20] Y. A.-R. I. Mohamed and H. H. Abdeltawab, "Robust energy management of a hybrid wind and flywheel energy storage system considering flywheel power losses minimization and grid-code constraints," IEEE Trans. Ind. Electron., vol. 63, no. 7, pp. 4242-4254, Jul. 2016.

[21] S. Muyeen, J. Tamura, and T. Murata, Stability Augmentation of a GridConnected Wind Farm. New York, NY, USA: Springer, 2008.

[22] M. Alam, K. Muttaqi, and D. Sutanto, "A novel approach for ramp-rate control of solar pv using energy storage to mitigate output fluctuations caused by cloud passing," IEEE Trans. Energy Convers., vol. 29, no. 2, pp. 507-518, Jun. 2014.

[23] I. De la Parra, J. Marcos, M. García, and L. Marroyo, "Storage requirements for pv power ramp-rate control in a pv fleet," Sol. Energy, vol. 118, pp. 426-440, 2015.

[24] S. G. Jayasinghe, D. M. Vilathgamuwa, and U. K. Madawala, "A dual inverter-based supercapacitor direct integration scheme for wind energy conversion systems," IEEE Trans. Ind. Appl., vol. 49, no. 3, pp. 10231030, May/Jun. 2013.

[25] P. Barrade, S. Delalay, and A. Rufer, "Direct connection of supercapacitors to photovoltaic panels with on-off maximum power point tracking," IEEE Trans. Sustain. Energy, vol. 3, no. 2, pp. 283-294, Apr. 2012.

[26] C. Y. Tang, Y.-T. Chen, and Y.-M. Chen, "PV power system with the multimode operation and low-voltage ride-through capability," IEEE Trans. Ind. Electron., vol. 62, no. 12, pp. 7524-7533, Dec. 2015.

[27] M. G. Villalva, J. R. Gazoli, and E. Ruppert Filho, "Comprehensive approach to modeling and simulation of photovoltaic arrays," IEEE Trans. Power Electron., vol. 24, no. 5, pp. 1198-1208, May 2009.

[28] G. M. S. Islam, A. Al-Durra, S. Muyeen, and J. Tamura, "Low voltage ride through capability enhancement of grid connected large-scale photovoltaic system," in Proc. 37th Annu. Conf. IEEE Ind. Electron. Soc., 2011, pp. 884-889.

[29] M. Mahmud, H. Pota, and M. Hossain, "Dynamic stability of three-phase grid-connected photovoltaic system using zero dynamic design approach," IEEE J. Photovolt., vol. 2, no. 4, pp. 564-571, Oct. 2012.

[30] V. Kaura and V. Blasko, "Operation of a phase locked loop system under distorted utility conditions," in Proc. 11th Annu. Appl. Power Electron. Conf. Expo., 1996, vol. 2, pp. 703-708.

[31] J. Pegueroles-Queralt, F. D. Bianchi, and O. Gomis-Bellmunt, "A power smoothing system based on supercapacitors for renewable distributed generation," IEEE Trans. Ind. Electron., vol. 62, no. 1, pp. 343-350, Jan. 2015.

[32] S. Muyeen, H. Hasanien, and J. Tamura, "Reduction of frequency fluctuation for wind farm connected power systems by an adaptive artificial neural network controlled energy capacitor system," IET Renew. Power Gener, vol. 6, no. 4, pp. 226-235, 2012.

[33] IEEE Recommended Practices and Requirements for Harmonic Control in Electrical Power Systems, IEEE Standard 519-1992, Apr. 1993, pp. $1-112$.

[34] N. Achaibou, M. Haddadi, and A. Malek, "Lead-acid batteries simulation including experimental validation," J. Power Sources, vol. 185, no. 2, pp. 1484-1491, 2008.

[35] T. Esram et al., "Comparison of photovoltaic array max- imum power point tracking techniques," IEEE Trans. Energy Convers., vol. 22, no. 2, pp. 439-449, Jul. 2007.

[36] S. Muyeen, R. Takahashi, and J. Tamura, "Electrolyzer switching strategy for hydrogen generation from variable speed wind generator," Electr. Power Syst. Res., vol. 81, no. 5, pp. 1171-1179, 2011.

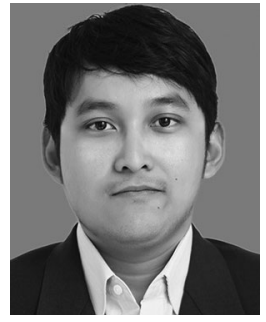

Yoga Sandi Perdana received the B.Sc. degree from the Bandung Institute of Technology, Bandung, Indonesia, in 2011, and the M.Sc. degree from the Khalifa University of Science and Technology, Abu Dhabi, UAE, in 2016, both in electrical engineering.

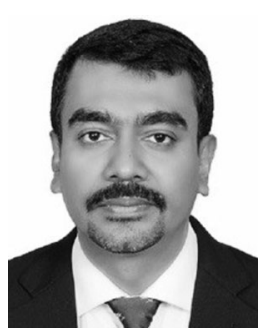

S. M. Muyeen (S'03-M'08-SM'12) received the B.Sc.Eng. degree from the Rajshahi University of Engineering and Technology, Rajshahi, Bangladesh, formerly known as the Rajshahi Institute of Technology, in 2000, and the M.Eng. and Ph.D. degrees from the Kitami Institute of Technology, Kitami, Japan, in 2005 and 2008, respectively, all in electrical and electronic engineering.

Currently, he is working as an Associate Professor with the Department of Electrical and Computer Engineering, Curtin University, Perth, W.A., Australia. He has authored or coauthored more than 175 articles in different journals and international conferences. He was the author or editor of six books. His research interests include power system stability and control, electrical machines, flexible ac transmission system devices, energy storage systems, renewable energy, and HVDC systems.

Dr. Muyeen has been a Keynote Speaker and an Invited Speaker at many international conferences, workshops, and universities. He is serving as an Editor/Associate Editor for many prestigious Journals from IEEE, IET, and other publishers including the IEEE TRANSACTIONS OF SUSTAINABLE ENERGY, IEEE POWER ENGINEERING LETTERS, IET Renewable Power Generation, and IET Generation, Transmission \& Distribution. He is a Fellow of Engineers Australia.

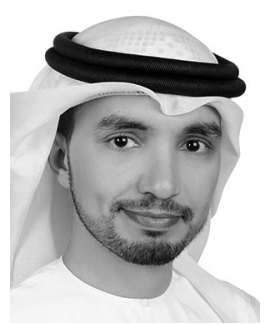

Ahmed Al-Durra (S'07-M'10-SM'14) received the $\mathrm{Ph} . \mathrm{D}$. degree in electrical and computer engineering (ECE) from Ohio State University, Columbus, OH, USA, in 2010

$\mathrm{He}$ is an Associate Professor with the ECE Department, Khalifa University of Science and Technology, Abu Dhabi, UAE. He has one US patent, one edited book, 11 book chapters, and more than 140 scientific articles in top-tier journals and refereed international conference proceedings. He has successfully accomplished and working on several research projects at international and national levels $(\sim \$ 6.5 \mathrm{M})$. He has supervised/co-supervised more than $20 \mathrm{Ph} . \mathrm{D}$./Master students. He is leading the Energy Systems, Control and Optimization Lab, ADNOC Research and Innovation Center, Abu Dhabi, UAE. His research interests include applications of control and estimation theory on power systems stability, micro and smart grids, renewable energy systems and integration, and process control.

Dr. Al-Durra is an Editor for the IEEE TRAnSACtions on Sustainable ENERGY. 


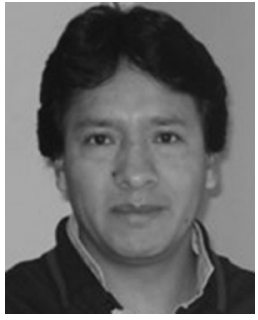

Helmo Kelis Morales-Paredes (S'10-M'11SM'18) received the B.S. degree from the San Agustin National University Arequipa, Arequipa, Peru, in 2002, and the M.Sc. and Ph.D. degrees from the University of Campinas, Campinas, Brazil, in 2006 and 2011, respectively, all in electrical engineering.

In 2009, he joined the Power Electronics Group, University of Padova, Padova, Italy, as a Visiting Student. In 2014, he joined the PEMC Group, University of Nottingham, Nottingham, U.K., as a Visiting Scholar. In 2018, he joined the ACEPS Group, Colorado School of Mines, Golden, CO, USA, as a Visiting Scholar. Since December 2011, he has been an Assistant Professor with the São Paulo State University, Sorocaba, SP, Brazil, where he is the Leader of the Group of Automation and Integrating Systems. His current research interests include power quality, power theories under nonsinusoidal condition, harmonics propagation, accountability, revenue metering, and power electronics applied for distributed and renewable energy systems.

Dr. Morales-Paredes is a member of the Brazilian Power Electronics Society and Brazilian Automation Society. He was a recipient of a Prize Paper Award from the IEEE TRANSACTIONS ON POWER ELECTRONICS in 2011.

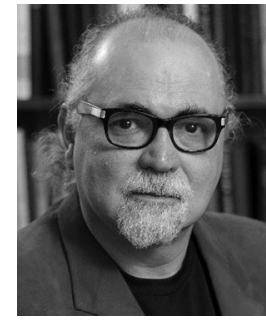

Marcelo Godoy Simões (S'89-M'95-SM'98-F'16) received the B.Sc. and M.Sc. degrees from the University of São Paulo, Sorocaba, SP, Brazil, the Ph.D. degree from The University of Tennessee, Knoxville, TN, USA, and the D.Sc. degree (Livre-Docência) from the University of São Paulo, in 1985, 1990, 1995, and 1998, respectively.

He was a US Fulbright Fellow for AY 2014-15, working with the Institute of Energy Technology, Aalborg University, Aalborg, Denmark. He is currently serving as a Faculty Senator with the Colorado School of Mines, Golden, CO, USA, and as a Vice-President for the American Association of University Professors Chapter with the Colorado School of Mines. He is a pioneer to apply neural networks and fuzzy logic in power electronics, motor drives, and renewable energy systems. His fuzzy logic based modeling and control for wind turbine optimization is used as a basis for advanced wind turbine control and it has been cited worldwide. His leadership in modeling fuel cells is internationally and highly influential in providing a basis for further developments in fuel cell automation control in many engineering applications. He made substantial and lasting contribution of artificial intelligence technology in many applications, power electronics and motor drives, fuzzy control of wind generation system, such as fuzzy logic based waveform estimation for power quality, neural network based estimation for vector-controlled motor drives, and integration of alternative energy systems to the electric grid through AI modeling based power electronics control.

Dr. Simões was a recipient of the "2018 IET Renewable Power Generation Premium Award." He is an IEEE Fellow, Class of 2016, with the citation: "for applications of artificial intelligence in control of power electronics systems." $\mathrm{He}$ is currently serving as the Chair for the IEEE Industrial Electronics Society Denver Chapter. 